\title{
Quantum chemical study of the mechanisms of oxidation of ethylene by Molybdyl and Tungstyl Chloride
}

\author{
RICHARD TIA*, EVANS ADEI, JOSEPH BAIDOO and JULIANA EDOR \\ Theoretical and Computational Chemistry Laboratory, Department of Chemistry, Kwame Nkrumah \\ University of Science and Technology, Kumasi, Ghana \\ e-mail: richtiagh@yahoo.com
}

MS received 23 November 2015; revised 24 February 2016; accepted 25 February 2016

\begin{abstract}
The mechanisms of oxidation of olefins with $\mathrm{MoO}_{2} \mathrm{Cl}_{2}$ and $\mathrm{WO}_{2} \mathrm{Cl}_{2}$ are studied with DFT. The formation of epoxide from these reactions is not very feasible by any of the postulated paths. If the epoxide precursor will form at all, it will arise via initial $[3+2]_{\mathrm{O}, \mathrm{Cl}}$ addition of ethene to $\mathrm{MoO}_{2} \mathrm{Cl}_{2}$ and $\mathrm{WO}_{2} \mathrm{Cl}_{2}$ to form an intermediate, followed by re-arrangement to form the precursor, from which the epoxide can be generated by hydrolysis. The chlorohydrin precursor was also found to originate from $[3+2]_{\mathrm{O}, \mathrm{Cl}}$ addition of ethene to $\mathrm{MO}_{2} \mathrm{Cl}_{2}$. The results also indicate that a dichloride is not a likely product in the oxidation of ethylene by molybdyl chloride. However, in the case of $\mathrm{WO}_{2} \mathrm{Cl}_{2}$, the formation of a dichloride may not be precluded. The formation of acetaldehyde and vinyl alcohol from the oxidation of ethylene does not appear energetically feasible with $\mathrm{MoO}_{2} \mathrm{Cl}_{2}$, but appears thermodynamically plausible with $\mathrm{WO}_{2} \mathrm{Cl}_{2}$. Thus, the oxidation of ethylene with $\mathrm{MoO}_{2} \mathrm{Cl}_{2}$ will most likely lead to the formation of chlorohydrins predominantly via $[3+2]_{\mathrm{O}, \mathrm{Cl}}$ addition; oxidation with $\mathrm{WO}_{2} \mathrm{Cl}_{2}$ may also form chlorohydrins, but only extremely slowly. The oxyhalides $\mathrm{MO}_{2} \mathrm{Cl}_{2}$ become weaker oxidants in the order $\mathrm{CrO}_{2} \mathrm{Cl}_{2}>>\mathrm{MoO}_{2} \mathrm{Cl} 2>\mathrm{WO}_{2} \mathrm{Cl}_{2}$. Corresponding to this, reactions involving reduction of the metal $[3+2]$ and $[2+1]$ show a sharp increase in barrier going from $\mathrm{Cr}$ to $\mathrm{W}$; reactions without a change in metal oxidation state $([2+2])$ show much smaller variations, which are possibly mainly determined by sterics.
\end{abstract}

Keywords. Olefin oxidation; epoxidation; computational; mechanisms

\section{Introduction}

High-valent transition metal oxo compounds, such as osmium tetraoxide $\left(\mathrm{OsO}_{4}\right)$, chromyl chloride $\left(\mathrm{CrCl}_{2} \mathrm{O}_{2}\right)$ and permanganate $\left(\mathrm{MnO}_{4}^{-}\right)$are known to be very strong oxidizing agents. In their reactions, an oxygen or a halogen is inserted into a $\mathrm{C}-\mathrm{H}$ linkage or added to an olefinic double bond, a property that has been utilized in a variety of applications ranging from organic synthesis to chemical vapor deposition to catalysis. A major interest is in the selectivity of the oxidation of organic compounds and the specificity of the product(s) formed from these reaction, ${ }^{1,2}$ since oxidations carried out this way is far more specific and relatively gentle compared to oxidations carried out through the direct application of elemental oxygen.

The mechanisms of the oxidation processes have been the subject of a lot of experimental and theoretical studies. ${ }^{3-11}$ For the reaction of osmium tetraoxide $\left(\mathrm{OsO}_{4}\right)$ with olefins, Criegee et al., ${ }^{12,13}$ proposed a concerted $[3+2]$ cycloaddition pathway (path A

*For correspondence in scheme 1). This proposal was widely accepted by organic chemists ${ }^{4,14,15}$ partly due to the fact that it is analogous with other dipolar cycloadditions. The product of the $[3+2]$ addition, a five-membered metallacycle (osma-2,5-dioxolane), was experimentally characterized, and upon hydrolysis gives diols. ${ }^{4}$

Experimental evidence shows that oxidation of olefins with osmium tetraoxide $\left(\mathrm{OsO}_{4}\right)$ and permanganate $\left(\mathrm{MnO}_{4}^{-}\right)$forms predominantly diols without significant epoxide formation. However, oxidation with chromyl chloride $\left(\mathrm{CrCl}_{2} \mathrm{O}_{2}\right)$ forms a complex mixture of products with predominantly epoxide formation. . $^{3,4,16}$ The main products in the oxidation of alkenes with $\mathrm{CrO}_{2} \mathrm{Cl}_{2}$ are epoxide, chlorohydrin and in some cases, vicinal dichloride, the formation of which could not be explained by Criegee's concerted pathway. Sharpless et al., ${ }^{3}$ therefore proposed a mechanism involving organometallic intermediates with chromium-carbon linkages. Particularly, the key feature in the formation of epoxide was postulated to be the involvement of a chromaoxetane, i.e., a four-membered cyclic compound formed via a $[2+2]$ interaction between the olefin and an oxo group on the chromium (path B in scheme 1). However, 


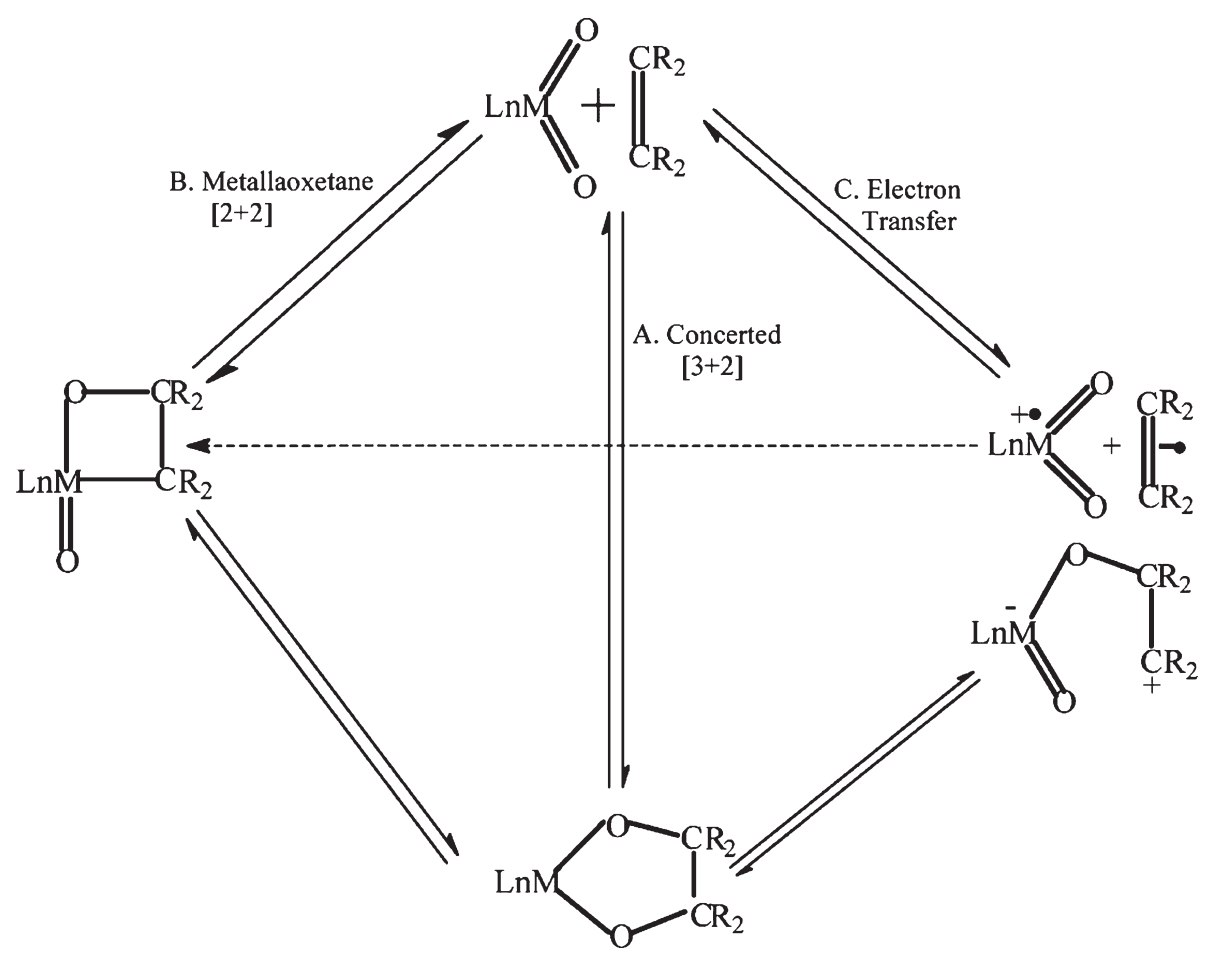

Scheme 1. Possible pathways for the reaction of $\mathrm{LnMO}_{2}$ with Alkene. ${ }^{18}$

the work of Tia and $\mathrm{Adei}^{7}$ showed that the oxidation of ethylene with $\mathrm{Cl}_{2} \mathrm{CrO}_{2}$ should form predominantly diols, chlorohydrins and to a less extent, dichlorides without significant epoxide formation.

Kochi et al. ${ }^{17}$ proposed a third mechanism (path $\mathrm{C}$ in scheme 1) to explain the oxidation of olefins by oxo transition metal complexes ${ }^{17}$ which involves an initial electron transfer, and addition of the odd electron intermediate to give a metallaoxetane and/or metalladiolate.

Ziegler et al., ${ }^{6}$ studied the $[2+2]$ and $[2+3]$ cycloaddition mechanisms for the osmium-catalyzed dihydroxylation of olefins using DFT with ammonia and ethylene chosen as models for the base and olefin respectively (scheme 2).

The results from this study indicated that the hypothesis by Sharpless et al., ${ }^{3}$ a [2+2] cycloaddition pathway involving the formation of a four-membered metallacycle as an intermediate should be ruled out because the activation barrier for the $[2+2]$ pathway was higher than the activation barrier for the $[3+2]$ pathway. Moreover, the addition of an $\mathrm{NH}_{3}$ ligand to the osmium catalyst did not reduce the $[2+2]$ energy barrier significantly. In contrast, it seemed more feasible that the dihydroxylation reaction proceeds through a $[2+3]$ mechanism leading to the formation of a five-membered ring dioxylate intermediate as proposed by Criegee et al., ${ }^{12,13}$ and supported by Corey et al. ${ }^{14,15}$ This pathway was found to be exothermic and involved a very small activation barrier of less than $2 \mathrm{kcal} / \mathrm{mol}$.

Rappé et al. ${ }^{19}$ studied the mechanism of the reaction of ethylene with chromyl chloride $\left(\mathrm{CrO}_{2} \mathrm{Cl}_{2}\right)$ and molybdyl chloride $\left(\mathrm{MoO}_{2} \mathrm{Cl}_{2}\right)$ with the GVB method, focusing on the energies of the intermediates. The results of this study provided support for the $[2+2]$ addition pathway to form a metallacyclobutane (metallaoxetane) intermediate, which in turn supports Sharpless's proposal that the organometallic intermediate is likely the common precursor from which all the oxygen-containing products that have been observed arise. Sharpless and Gobel provided additional $n$ of the stepwise addition pathway by way of non-linear Eyring enantioselectivity-reciprocal of temperature plots for

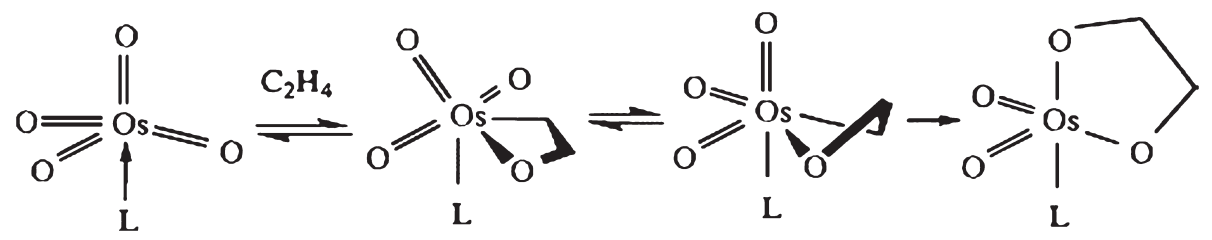

Scheme 2. Postulated intermediates in the base-free and base-assisted addition of $\mathrm{OsO}_{4}$ to olefins. 
asymmetric dihydroxylations. Computations of the $[2+2]$ and $[3+2]$ activation barriers for the reactions of $\mathrm{OsO}_{4}$ with ethylene ${ }^{5,6,20}$ showed that the barriers of the $[2+2]$ addition to form the four-membered metallaoxetane ring was very much higher than the barriers for the $[3+2]$ addition to form the fivemembered osma-2,5-dioxalane, which indicated that the reaction follows the concerted [3+2] addition pathway. The work of Houk et al., ${ }^{21}$ also supported the concerted reaction pathway for the addition of $\mathrm{OsO}_{4}$ with ethylene. For the chromyl chloride $\left(\mathrm{CrO}_{2} \mathrm{Cl}_{2}\right)$ system, Ziegler et al., ${ }^{22}$ performed DFT calculations on the addition of ethene across chromium-oxygen bonds and found the $[3+2]$ addition to form the five-membered ring to be more favorable than the $[2+2]$ addition to form the four-membered cyclic chromaoxetane. In another study, Ziegler et al., ${ }^{23}$ found that contrary to Sharpless' assumption, the formation of the epoxide precursor from the reaction between $\mathrm{CrO}_{2} \mathrm{Cl}_{2}$ and ethylene does not involve an organometallic intermediate arising from $[2+2]$ addition but rather from an ester intermediate formed from the $[3+2]$ addition of ethene to the chromium-oxygen bonds in $\mathrm{CrO}_{2} \mathrm{Cl}_{2}$. A density functional theory study on the oxidation of ethene by ruthenium tetraoxide, a well-known active catalyst, by Strassner and Drees, ${ }^{24}$ proposed that the reaction follows a $[3+2]$ addition pathway on the singlet surface, which was found to be $22 \mathrm{kcal} / \mathrm{mol}$ lower in activation energy than the $[2+2]$ cycloaddition pathway.

In a DFT B3LYP/6-31G* study by Tia and Adei ${ }^{7}$ the activation barrier for the $[3+2]$ addition pathway was found to be lower than that for the $[2+2]$ pathway, but the dioxylate formed from the $[3+2]$ pathway was found to be too stable to be rearranged to the epoxide precursor. It was therefore argued that if an epoxide is formed at all, it must arise from [2 +2$]$ addition and not by the $[3+2]$ addition. The energetics from this study indicates that the reaction of ethylene with $\mathrm{Cl}_{2} \mathrm{CrO}_{2}$ should form diols predominantly. In another DFT study, ${ }^{8}$ they found that in the reaction of ethylene with osmyl chloride $\left(\mathrm{Os}_{2} \mathrm{Cl}_{2}\right)$, the $[2+2]$ pathway leading to the formation of metalloxetane was more favoured than the $[3+2]$ pathway leading to the dioxylate, whereas for the $\mathrm{OsO}_{4}$ the $[3+2]$ pathway was favored.

It is clear from the literature that there is no agreement on the most preferred pathway for the oxidation of olefins with transition metal oxo-complexes. This work aims at extending the work of Tia and Adei $^{7}$ to include Mo and W, the other members of the group VI metals, so as to draw group trends. We have already shown interesting group trends in the oxidation of olefins with group VII metal oxo complexes. ${ }^{10}$ The mechanism of the oxidation of ethylene with $\mathrm{MoO}_{2} \mathrm{Cl}_{2}$ and $\mathrm{WO}_{2} \mathrm{Cl}_{2}$ leading ultimately to the formation of ethylene oxide (epoxide), 1,2-chlorohydrin, 1,2-dichloroethane, vinyl alcohol and acetaldehyde (schemes 3 and 4) was investigated theoretically using hybrid and meta-hybrid density functional theory. The calculations were carried out at both B3LYP and MO6 levels of theory and the results were compared to assess the performance of the two levels.

\section{Computational Procedure}

We performed all the computations with the Spartan ${ }^{25}$ computational chemistry package developed by Wavefunction, Inc, versions 2008V1.2.0 and 2010V1.2.0, using the Becke-three-parameter Lee-Yang-Parr (B3LYP) hybrid exchange-correlational functional and the MO6 hybrid functional. The B3LYP functional, a Hartree-Fock DFT hybrid functional, is made up of the exchange-correlation energy from the local spin-density approximation (LSDA) method, 20\% of the difference between the Hartree-Fock exchange energy (Kohn-Sham exchange energy) and the LSDA exchange energy, $72 \%$ of the Becke exchange potential (which includes the 1988 correction), ${ }^{26,27} 81 \%$ of the Lee-Yang-Parr correlation potential ${ }^{28}$ and $19 \%$ of the Vosko-Wilk-Nusair potential ${ }^{29}$ and is one of the most widely used exchange-correlation functionals in organometallic chemistry. The MO6 functional ${ }^{30}$ is a global hybrid meta-generalized gradient approximation (meta-GGA) with $27 \%$ of Hartree-Fock exchange, leading to a well-balanced functional for overall good performance for chemistry. It has thus been recommended for application in organometallic and inorganometallic chemistry. ${ }^{31}$ The atoms hydrogenchlorine were described with the 6-31G (d) basis set while the metals Mo and $\mathrm{W}$ were described with the lanl2tz basis set. ${ }^{32-36}$

Spartan uses a graphical model builder for input preparation. Molecules were constructed and minimized interactively using an appropriate molecular mechanics force field. All structural optimizations were done without symmetry restrictions. Normal mode analysis was performed to verify the nature of the stationary points located. Minima, representing reactants, intermediates and products were shown to have no imaginary frequencies.

Guess structures for transition state calculations were obtained by first constraining specific bonds along the reaction coordinates at fixed lengths while the remaining internal coordinates were fully optimized. This procedure gives an approximate transition state guess 
<smiles></smiles>

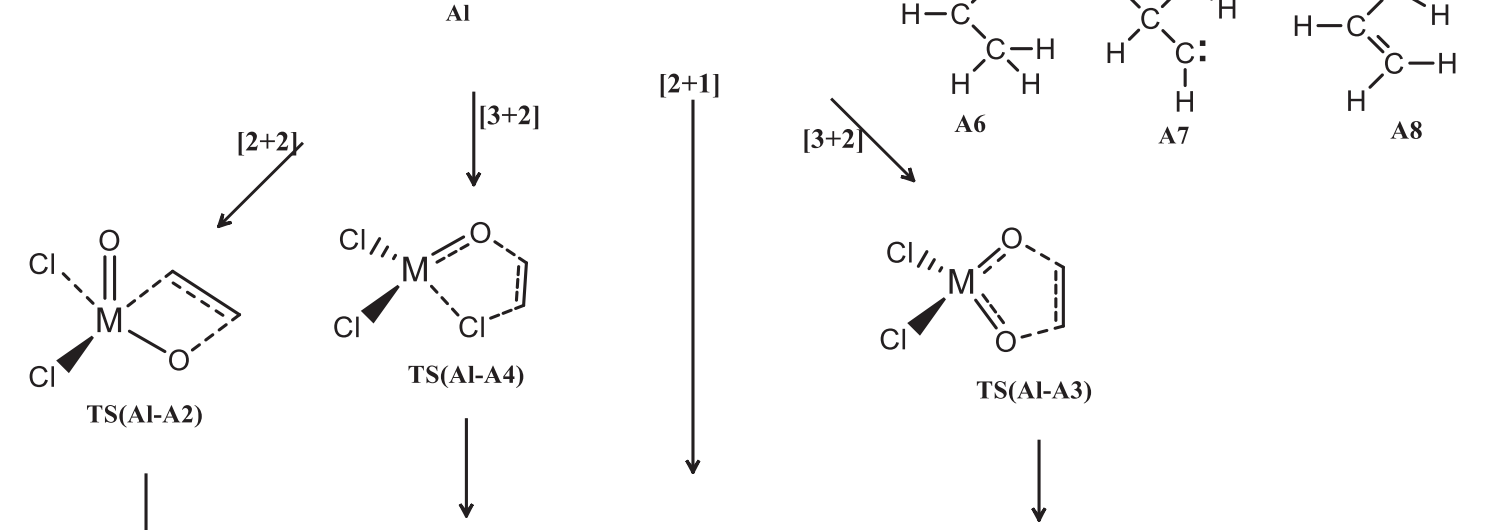<smiles>O=[W]1(Cl)CCO1</smiles><smiles>O=[W]1(Cl)OCC[Al]1</smiles><smiles>CCCC</smiles><smiles>O=[W](Cl)(Cl)O[Ga]1C=C1</smiles><smiles>Cl[W]1(Cl)OCCO1</smiles>

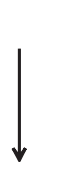

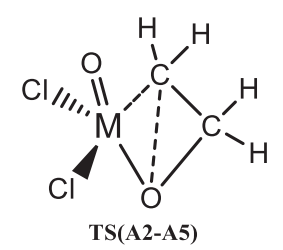<smiles>O=[W]1(Cl)OC2[SiH2]C21</smiles><smiles>[Mg][Mg][Mg]</smiles><smiles>O=[N+](Cl)[W](=O)(Cl)Cl</smiles><smiles>CI</smiles><smiles>CI</smiles><smiles>[1H]C([1H])([1H])O[W](=O)(Cl)Cl</smiles><smiles>[CH][C@H]([CH][IH+])O[W](=O)(Cl)Cl</smiles><smiles>[H]/C=C\O[W](=O)(Cl)Cl</smiles><smiles>C1CCCCC1</smiles><smiles>[H][Y14]1=C[C@H](Cl)[C@H]([CH])O1</smiles>

TS(A3-A5)<smiles>[CH]CC</smiles><smiles>O=[W](Cl)(Cl)OC1CC1</smiles><smiles>C</smiles> 


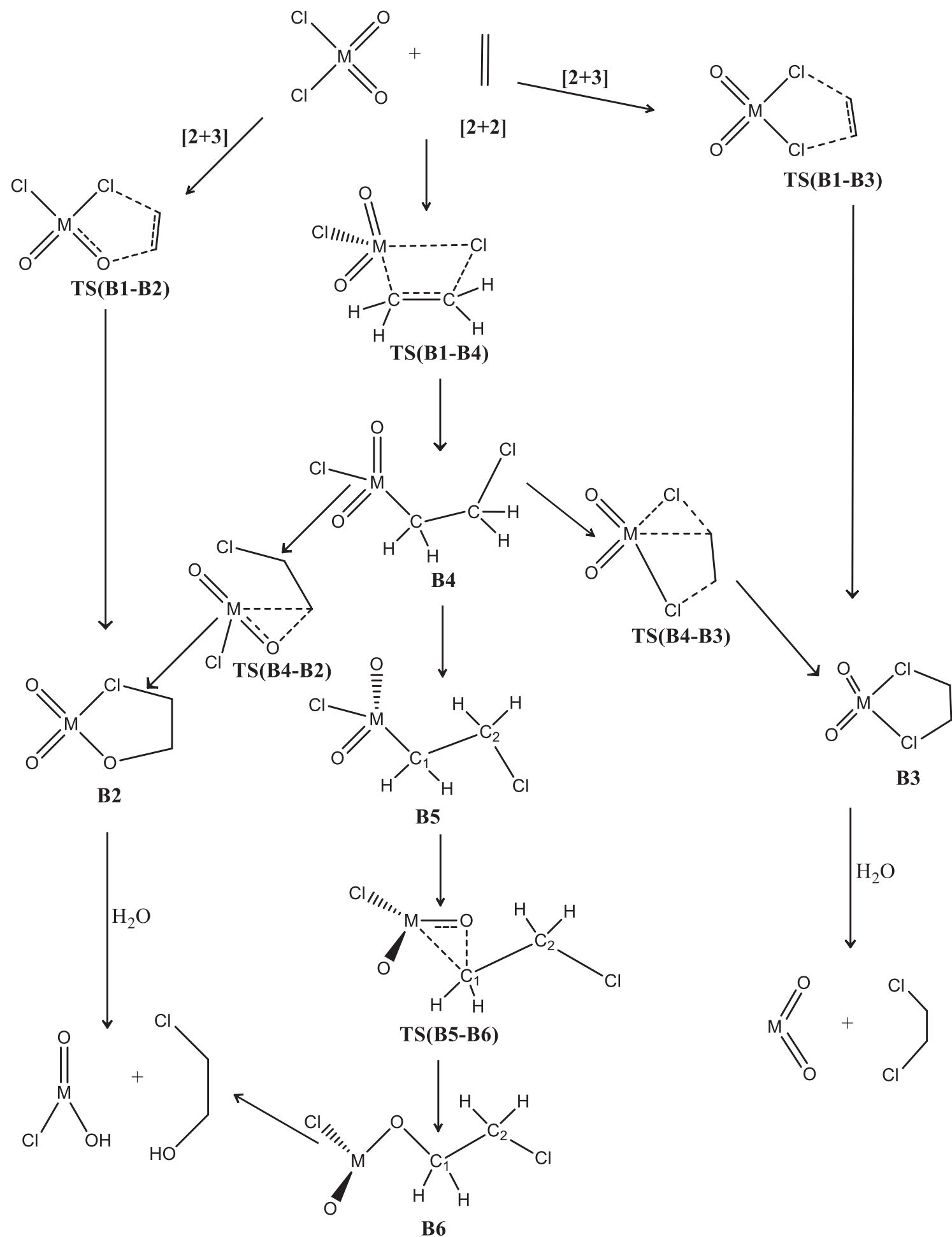

Scheme 4. Proposed mechanisms of the $\mathrm{MO}_{2} \mathrm{Cl}_{2}$-mediated formation of chlorohydrins and dichlorides. ${ }^{7}$

\section{Results and Discussion}

\subsection{Formation of the epoxide precursor}

In the transformation of ethylene to the epoxide, the addition process can be viewed as that of a one oxygen atom transfer. From scheme 3, the metal center is involved in a reduction from $d^{0}$ in the reactant $\mathbf{A} \mathbf{1}$, to $d^{2}$ in the products. A common direct precursor $\mathbf{A 5}$ has been suggested in all the postulated mechanisms, no matter the pathway involved in the transformation. This species, first postulated by Sharpless et al. ${ }^{3}$ as the immediate precursor of epoxide, was again proposed by Limberg et al., ${ }^{37,38}$ also as the oxirane adduct intermediate leading to acetaldehyde. 
From scheme 3, it is seen that species A5 could in principle arise from four different pathways:

(1) a two-step process involving initial $[2+2]$ addition of ethylene across the $\mathrm{M}=\mathrm{O}$ bond of $\mathrm{MO}_{2} \mathrm{Cl}_{2}$;

(2) a two-step process involving initial $[3+2]$ addition of ethylene across the two oxygen atoms of $\mathrm{MO}_{2} \mathrm{Cl}_{2}$

(3) a two-step process involving [3+2] addition of ethylene across the oxygen and chlorine atoms of $\mathrm{MO}_{2} \mathrm{Cl}_{2}$, and

(4) a one-step direct addition of ethylene to one oxygen atom of $\mathrm{MO}_{2} \mathrm{Cl}_{2}$.

The $[2+2]$ and $[3+2]$ pathways are both two-step processes. The $[2+2]$ involves a metalloxetane intermediate $(\mathbf{A 2})$ whereas the $[3+2]$ pathway involves an ester complex intermediate (A3).

The energy profiles at the MO6 levels of theory are reported and discussed here. The profiles at the B3LYP level as well as the full set of optimized geometries for all the systems are reported in the Electronic Supplementary Information.

3.1a Molybdenum complex: The activation barrier for the formation of the molybdaoxetane by $[2+2]$ addition through the metal-oxygen bond is $18.9 \mathrm{kcal} / \mathrm{mol}$ (figure 1). In transition state TS[A1-A2], the Mo-C forming-bond is almost completely formed whereas the $\mathrm{C}-\mathrm{O}$ bond is still far from being formed. Therefore the critical bond activity in TS[A1-A2] is the formation of the $\mathrm{C}-\mathrm{O}$ bond and this is seen in both the B3LYP and MO6 levels. The molybdaoxetane intermediate A2 which results has an exothermicity of $0.4 \mathrm{kcal} / \mathrm{mol}$ on the singlet surface. Triplet $\mathbf{A 2}$ is exothermic by $21.2 \mathrm{kcal} / \mathrm{mol}$. Thus the triplet intermediate is far less stable than the singlet. The formation of the epoxide precursor $\mathbf{A 5}$ from the molybdaoxetane intermediate A2 through transition state TS [A2-A5] has an activation barrier of $41.3 \mathrm{kcal} / \mathrm{mol}$ and a reaction energy of $10.3 \mathrm{kcalmol}^{-1}$.

The $[3+2]$ addition across the two oxygen atoms of molybdyl chloride leads to the formation of a molybdadioxylate intermediate $\mathbf{A 3}$ which is endothermic by $9.4 \mathrm{kcal} / \mathrm{mol}$ on the singlet and exothermic by $1.2 \mathrm{kcal} / \mathrm{mol}$ on the triplet surface. The geometry of the transition state at both levels of theory indicates a concerted and synchronous addition type. A comparison between the $\mathrm{C}-\mathrm{O}$ bond lengths in the transition state and the product shows that it is an early transition state. The activation barrier for the $[3+2]$ addition of ethylene across the $\mathrm{O}=\mathrm{M}=\mathrm{O}$ bonds of $\mathrm{MoO}_{2} \mathrm{Cl}_{2}$ is $30.2 \mathrm{kcal} / \mathrm{mol}$ and $44.3 \mathrm{kcal} / \mathrm{mol}$ on the singlet and

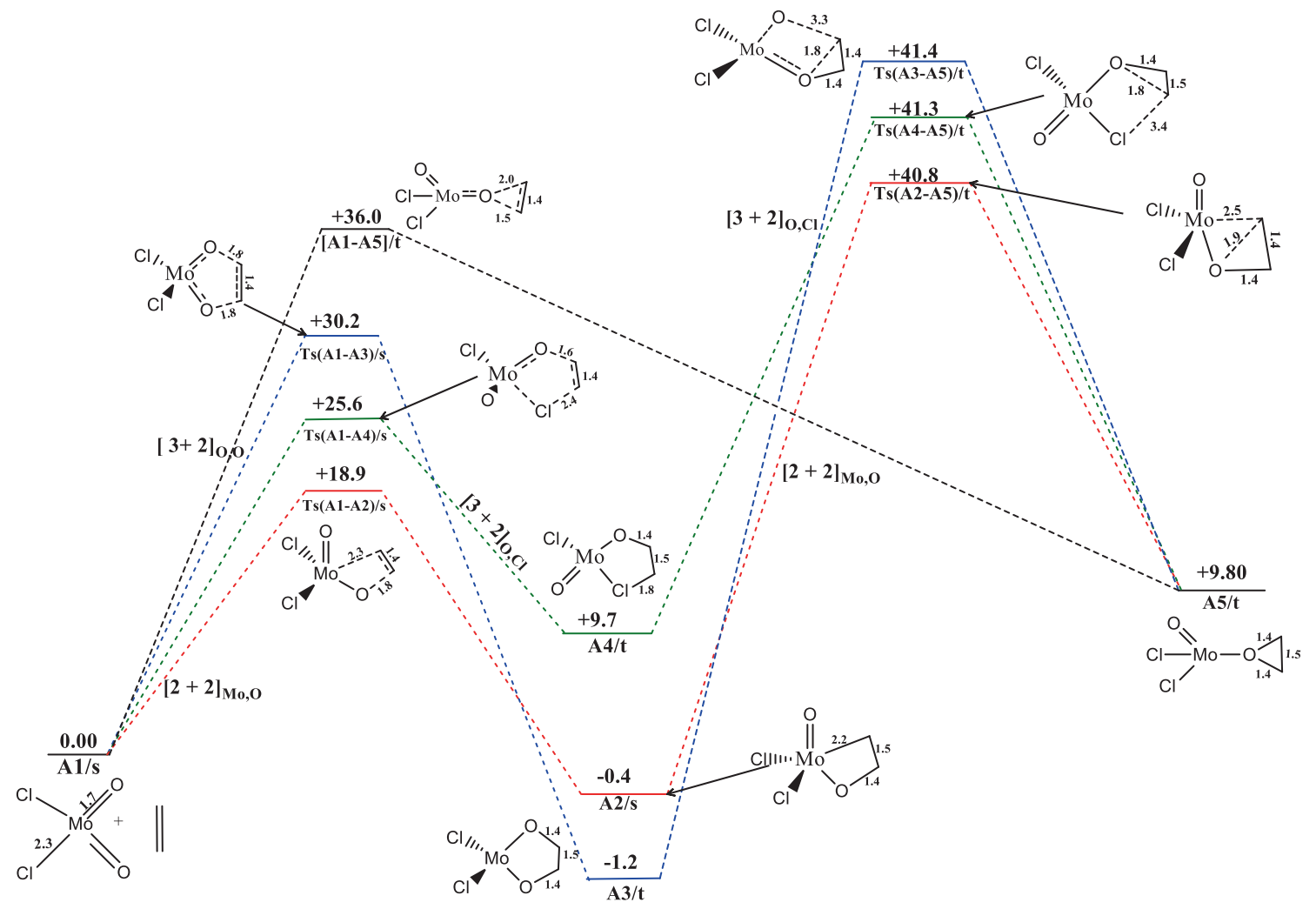

Figure 1. Reaction profile for the formation of the epoxide precursor from the addition of $\mathrm{MoO}_{2} \mathrm{Cl}_{2}$ and ethylene at MO6 level. There is spin cross-over intersystem crossing from the singlet reactant A1/s to the triplet epoxide precursor A5/t ( $\mathrm{s}=$ singlet state, $\mathrm{t}=$ triplet). Energy in $\mathrm{kcal} / \mathrm{mol}$. 


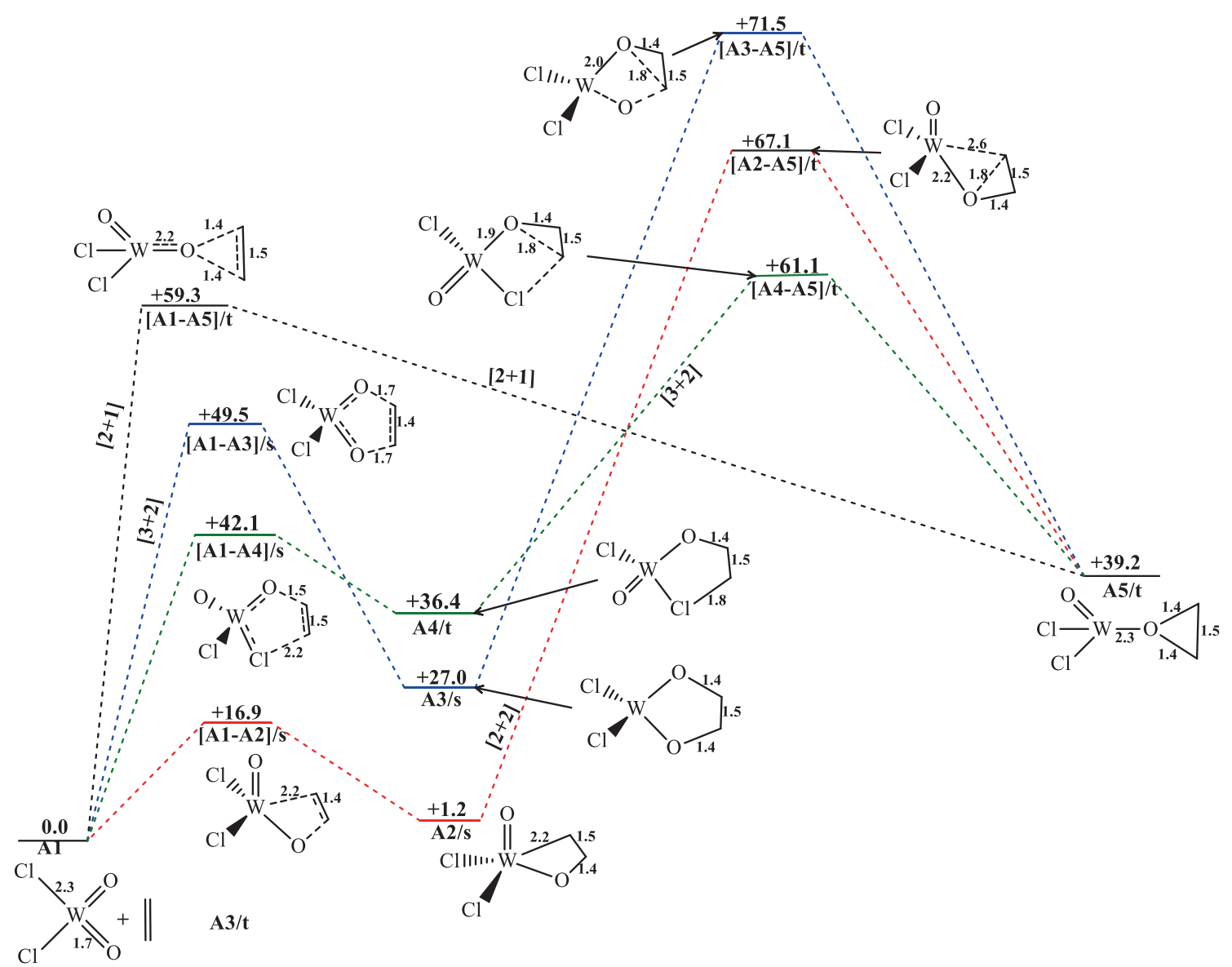

Figure 2. Reaction profile for the formation of the epoxide precursor from the addition of $\mathrm{WO}_{2} \mathrm{Cl}_{2}$ to ethylene at the MO6 level. There is spin cross-over intersystem crossing from the singlet reactant A1/s to the triplet epoxide precursor A5/t $(\mathrm{s}=$ singlet state, $\mathrm{t}=$ triplet). Energy in $\mathrm{kcal} / \mathrm{mol}$.

triplet PES, respectively. The rearrangement of the molybdadioxylate intermediate $\mathbf{A} \mathbf{3}$ to the epoxide precursor $\mathbf{A 5}$ has an activation barrier of $39.2 \mathrm{kcal} / \mathrm{mol}$ and $42.6 \mathrm{kcal} / \mathrm{mol}$ on the singlet and triplet surfaces respectively.

The $[3+2]$ addition of ethylene across the oxygen and chlorine atoms of $\mathrm{MoO}_{2} \mathrm{Cl}_{2}$ has an activation barrier of $25.6 \mathrm{kcal} / \mathrm{mol}$ on the singlet and $31.3 \mathrm{kcal} / \mathrm{mol}$ on the triplet surfaces, respectively, resulting in intermediates that are endothermic by $14.9 \mathrm{kcal} / \mathrm{mol}$ on the singlet and $9.7 \mathrm{kcal} / \mathrm{mol}$ on the triplet surfaces respectively. The barriers for the conversion of the intermediate to the epoxide precursor are 32.8 and $31.6 \mathrm{kcal} / \mathrm{mol}$ on the singlet and triplet surfaces, respectively, resulting in intermediates that are 19.7 and $0.1 \mathrm{kcal} / \mathrm{mol}$ endothermic, respectively, on the singlet and triplet surfaces. Thus overall, the formation of A5 by $[2+2]$ addition of ethylene across the metal-oxygen bond of $\mathrm{MoO}_{2} \mathrm{Cl}_{2}$ cannot compete favourably, both kinetically and thermodynamically, with formation by $[3+2]$ addition of ethylene across the chlorine and oxygen atoms. 3.1b Tungsten complex: The activation barrier for the $[2+2]$ addition of ethylene across the $\mathrm{W}-\mathrm{O}$ bonds of $\mathrm{WO}_{2} \mathrm{Cl}_{2}$ leading to the tungstaoxetane $\mathbf{A 2}$ through transition state TS[A1-A2] is $16.9 \mathrm{kcal} / \mathrm{mol}$ (figure 2). In transition state TS[A1-A2], the W-C forming- bond is almost completely formed whereas the $\mathrm{C}-\mathrm{O}$ bond is still far from being formed. Thus the critical bond activity in TS[A1-A2] is the formation of the $\mathrm{C}-\mathrm{O}$ bond. This bond activity has been observed in both levels of theory. The resulting tungstaoxetane adduct A2 (singlet) is $1.2 \mathrm{kcal} / \mathrm{mol}$ endothermic. No triplet $\mathbf{A} 2$ or TS[A1A2] was located on the surface at either levels of theory. The rearrangement of the tungstaoxetane $\mathbf{A} 2$ to the epoxide precursor through transition state TS[A2-A5] has activation barriers and an endothermicities of 65.9 and $38.0 \mathrm{kcal} \mathrm{mol}^{-1}$ respectively.

The $[3+2]$ addition across the $\mathrm{O}=\mathrm{W}-\mathrm{O}$ bonds of tungstyl choride leads to the formation of an ester complex intermediate $\mathbf{A 3}$ through the singlet transition state TS [A1-A3] with an activation barrier of $49.5 \mathrm{kcal}$ $\mathrm{mol}^{-1}$. Frenking et al., ${ }^{5}$ Morokuma et al., ${ }^{20}$ Ziegler et al., ${ }^{22,23}$ and $\mathrm{Tia}^{7}$ reported barrier for this route to 
be less than $10 \mathrm{kcal} / \mathrm{mol}$ for the chromium adduct. The geometry of the transition state TS [A1-A3] at both levels of theory indicates a concerted and synchronous addition. A comparison between the $\mathrm{C}-\mathrm{O}$ bond lengths in the transition state and the product shows that it is an early transition state. The ester complex intermediate $\mathbf{A 3}$ is $27.0 \mathrm{kcal} / \mathrm{mol}$ and $53.4 \mathrm{kcal} / \mathrm{mol}$ endothermic on the singlet and triplet surfaces, respectively. The activation barrier and reaction enthalpy for the formation of the epoxide precursor $\mathbf{A 5}$ from the ester complex are $44.5 \mathrm{kcal} / \mathrm{mol}$ and $12.2 \mathrm{kcal} / \mathrm{mol}$, respectively. Triplet TS [A1-A3] was located at the MO6 to be $53.4 \mathrm{kcal} / \mathrm{mol}$ above the reactant while triplet TS [A3A5] was $44.5 \mathrm{kcal} / \mathrm{mol}$ above the reactants. No triplet TS[A1-A3] and TS[A3-A5] was found at the B3LYP level.

Another pathway proposed for the formation of species $\mathbf{A 5}$ is through the [3+2] addition across the $\mathrm{O}=\mathrm{W}-\mathrm{Cl}$ bonds of $\mathrm{WO}_{2} \mathrm{Cl}_{2}$. At the MO6 level, the first step of this process has a barrier of $42.1 \mathrm{kcal} / \mathrm{mol}$ and the second step has a barrier of $24.7 \mathrm{kcal} / \mathrm{mol}$. An exhaustive search on both the singlet and triplet PES at the B3LYP level however could not locate the structure A4 but TS [A1-A4] was located on the triplet surface and found to be $56.0 \mathrm{kcal} \mathrm{mol}^{-1}$.

This study indicates that even though in the first step of the epoxide precursor formation, the $[2+2]$ addition across the $\mathrm{W}=\mathrm{O}$ bonds is the most favorable pathway, conversion of the tungstaoxetane intermediate $\mathbf{A} \mathbf{2}$ to the epoxide precursor involves a very high activation barrier and the epoxide precursor is therefore not likely to be formed from the tungstaoxetane intermediate. Also, the epoxide precursor is not likely to be formed from the direct $[2+1]$ addition pathway due to the high energy barrier of $59.3 \mathrm{kcal} / \mathrm{mol}$. From the two [3+ 2] addition pathways, both the first and second steps favor the $[3+2]$ addition across the $\mathrm{O}=\mathrm{W}-\mathrm{Cl}$ bonds of $\mathrm{WO}_{2} \mathrm{Cl}_{2}$. Hence if the epoxide forms at all, it will be formed by the $[3+2]$ addition across the oxygen and chlorine atoms of $\mathrm{WO}_{2} \mathrm{Cl}_{2}$ since the highest energy barrier along this pathway is $42.1 \mathrm{kcal} / \mathrm{mol}$ as compared to $49.5 \mathrm{kcal} / \mathrm{mol}, 59.3 \mathrm{kcal} / \mathrm{mol}$ and $65.8 \mathrm{kcal} / \mathrm{mol}$ for the $[3+2]_{\mathrm{O}, \mathrm{O}} ;[2+1]_{\mathrm{O}, \mathrm{Cl}}$ and $[2+2]$ pathways, respectively, at the MO6 level.

\subsection{Formation of chlorohydrin and dichloroethane}

Three mechanisms have been proposed for chlorohydrin precursor formation by Tia and $\mathrm{Adei}^{7}$ as shown in scheme 4. These are

(a) a one-step reaction through $[3+2]_{\mathrm{O}, \mathrm{Cl}}$ addition to form the chlorohydrin precursor (i.e., $\mathbf{B 2}$ in scheme 4); (b) a two-step reaction through $[2+2]_{\mathrm{M}, \mathrm{Cl}}$ addition to form an intermediate $\mathbf{B} 4$ which then undergoes re-arrangement to form the chlorohydrin precursor $\mathbf{B} 2$ and

(c) the formation of another chlorohydrin precursor B6 from the re-arrangement of intermediate B4 as shown in scheme 4 .

The conversion of alkenes into 1,2-chlorohydrins was originally proposed by Sharpless et al., (1977) to arise from cis-addition of the elements of $\mathrm{HOCl}$ across the $\mathrm{C}=\mathrm{C}$ bond of the alkene, which is highly selective. Chlorohydrins arising from trans-addition were found to be secondary products derived by opening of the epoxide ring. Limberg et al., ${ }^{37,38}$ also postulated the presence of $\mathrm{CrOCH}_{2} \mathrm{CH}_{2} \mathrm{Cl}$ fragments in the Étard complex, which is consistent with the structure of $\mathbf{B 6}$, in a matrix isolation study of the reaction between $\mathrm{CrO}_{2} \mathrm{Cl}_{2}$ and ethylene. Scheme 4 also shows that the dichloride precursor could be formed by $[3+2]_{\mathrm{Cl}, \mathrm{Cl}}$ addition of ethylene across the $\mathrm{Cl}-\mathrm{M}-\mathrm{Cl}$ bonds of the complexes.

3.2a Molybdenum complex: The activation barriers for the one-step [3+2] addition of ethylene across the oxygen and chlorine atoms of $\mathrm{Cl}_{2} \mathrm{MoO}_{2}$ is $25.6 \mathrm{kcal} / \mathrm{mol}$ on the singlet and $31.3 \mathrm{kcal} / \mathrm{mol}$ on the triplet (figure 3). Species $\mathbf{B 2}$ is endothermic by $14.9 \mathrm{kcal} / \mathrm{mol}$ on the singlet and $9.7 \mathrm{kcal} / \mathrm{mol}$ on the triplet.

In the other one-step $[3+2]$ addition across the two chlorine atoms for the formation of $\mathbf{B 3}$ through TS[B1-B3], neither the transition state TS[B1-B3] nor the dichloride precursor was located at the singlet and triplet PES for both B3LYP and MO6. The transition states TS[B4-B2] andTS[B4-B3] involved in the twostep formation of $\mathbf{B 2}$ and $\mathbf{B 3}$, respectively, were not located after an exhaustive search.

Along the second proposed pathway for the formation of chlorohydrins in scheme 4, species B5 which is $0.17 \mathrm{kcal} / \mathrm{mol}$ less stable than $\mathbf{B} 4$ is formed when $\mathbf{B} 4$ undergoes rotation about the $\mathrm{C}_{1}-\mathrm{C}_{2}$ bond. The energy barrier for the conversion of $\mathbf{B 5}$ to the chlorohydrin precursor $\mathrm{B} 6$ by the breaking of the Mo-C bond and the formation of the $\mathrm{C}-\mathrm{O}$ bond is $55.84 \mathrm{kcal} / \mathrm{mol}$ on the singlet PES. Thus for the $\mathrm{MoO}_{2} \mathrm{Cl}_{2}$, the preferred pathway for the chlorohydrin precursor is by concerted $[3+2]_{\mathrm{O}, \mathrm{Cl}}$ addition.

3.2b Tungsten complex: In the one-step $[3+2]$ addition across the two chlorine atoms for the formation of B3 through TS[B1-B3], both the singlet and triplet dichloride $\mathbf{B 3}$ were located at B3LYP and MO6 


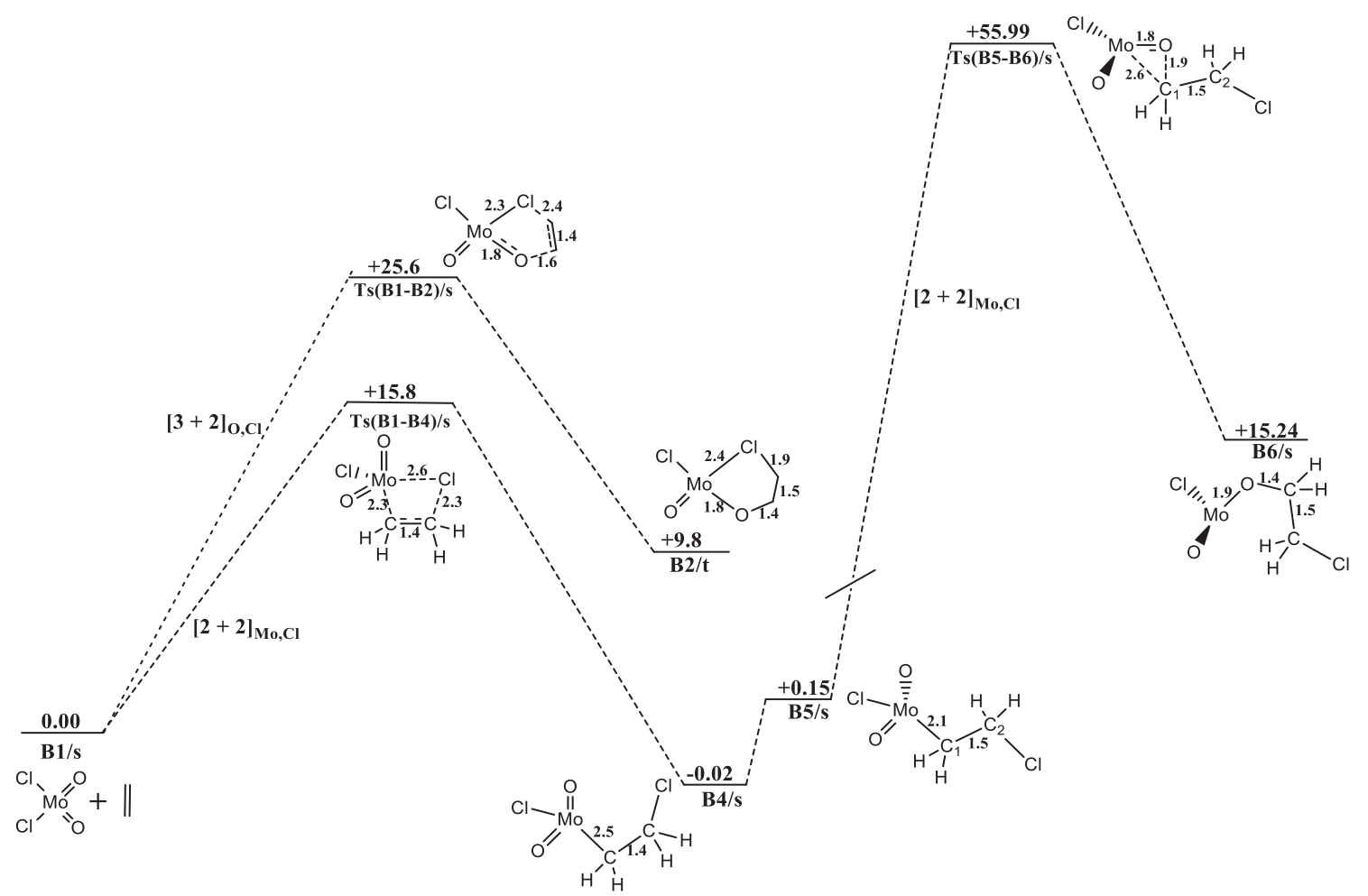

Figure 3. Reaction profile of mechanism for the formation of the 1,2-chlorohydrin precursor from the addition of $\mathrm{MoO}_{2} \mathrm{Cl}_{2}$ to ethylene at MO6. There is spin cross-over intersystem crossing from the singlet reactant $\mathbf{B} 1 / \mathbf{s}$ to the triplet $\mathbf{B 2} / \mathbf{t}$ ( $\mathrm{s}=$ singlet state, $\mathrm{t}=$ triplet). Energy in $\mathrm{kcal} / \mathrm{mol}$.

levels (figure 4) but transition state TS [B1-B3] linking the reactants to the precursor could be not located at either level. The singlet $\mathbf{B 3}$ is $82.3 \mathrm{kcal} / \mathrm{mol}$ more stable than the separated reactants while the triplet $\mathbf{B 3}$ is $86.6 \mathrm{kcal} / \mathrm{mol}$ more stable than the separated reactants but no transition state for its formation was located.

The activation barriers for the $[3+2]$ addition across the oxygen and chlorine atoms, also a one-step process, are $42.1 \mathrm{kcal} / \mathrm{mol}$ and $52.9 \mathrm{kcal} / \mathrm{mol}$, respectively, on the singlet and triplet surfaces. Furthermore, the product B2 was found to be $40.0 \mathrm{kcal} / \mathrm{mol}$ and $36.4 \mathrm{kcal} / \mathrm{mol}$ endothermic on the singlet and triplet surfaces respectively. Also, the transition states involved in the twostep formation of $\mathbf{B 2}$ and $\mathbf{B 3}$ were not located in this study.

Along the third proposed pathway for the formation of chlorohydrins (scheme 4), species B4 undergoes rotation about the $\mathrm{C}_{1}-\mathrm{C}_{2}$ bond to form species $\mathbf{B 5}$ which is $0.2 \mathrm{kcal} / \mathrm{mol}$ less stable than $\mathbf{B 4}$. Species B6, which generates the chlorohydrin, is formed from $\mathbf{B 5}$ by the breaking of the W-C bond and formation of the $\mathrm{C}-\mathrm{O}$ bond. The energy barrier for this transition through TS[B5-B6] is $64.6 \mathrm{kcal} \mathrm{mol}^{-1}$, with an endothermicity of $32.9 \mathrm{kcal} / \mathrm{mol}$ on the singlet surface. Thus the formation of a chlorohydrin precursor is not likely in the oxidation of ethylene with $\mathrm{WO}_{2} \mathrm{Cl}_{2}$.

\subsection{Formation of acetaldehyde and vinyl alcohol}

Species A5 was postulated by Limberg et al., ${ }^{37,38}$ as the oxirane adduct intermediate leading to acetaldehyde, when the epoxide ring is opened. The products of the epoxide ring-opening were therefore localized on both the singlet and triplet potential energy surfaces.

3.3a Molybdenum complex: The singlet and triplet transition state TS[A5-X] for epoxide ring-opening were not obtained at both B3LYP and MO6. The singlet A7 was 92.6 and $81.2 \mathrm{kcal} / \mathrm{mol}$ endothermic, at B3LYP and MO6 respectively. Triplet A7 was not located at either the B3LYP or MO6. Species A8, which produces vinyl alcohol when it undergoes Mo-O single bond cleavage results from a 1,2-hydride shift from the secondary carbon to the terminal carbon of A7. At B3LYP and MO6, species A8 was endothermic by 18.0 and $12.4 \mathrm{kcal} / \mathrm{mol}$ respectively on the singlet PES. The triplet $\mathbf{A 8}$ has also been computed to be $5.6 \mathrm{kcal} / \mathrm{mol}$ exothermic at MO6 while no triplet A8 was located at B3LYP. In an attempt to optimize $\mathbf{A 8}$ on the singlet PES, the acetaldehyde precursor A6 was obtained and was 3.7 and $10.8 \mathrm{kcal} / \mathrm{mol}$ exothermic for the singlet species, at B3LYP and MO6 respectively, making it the global minimum on the singlet PES at both levels 


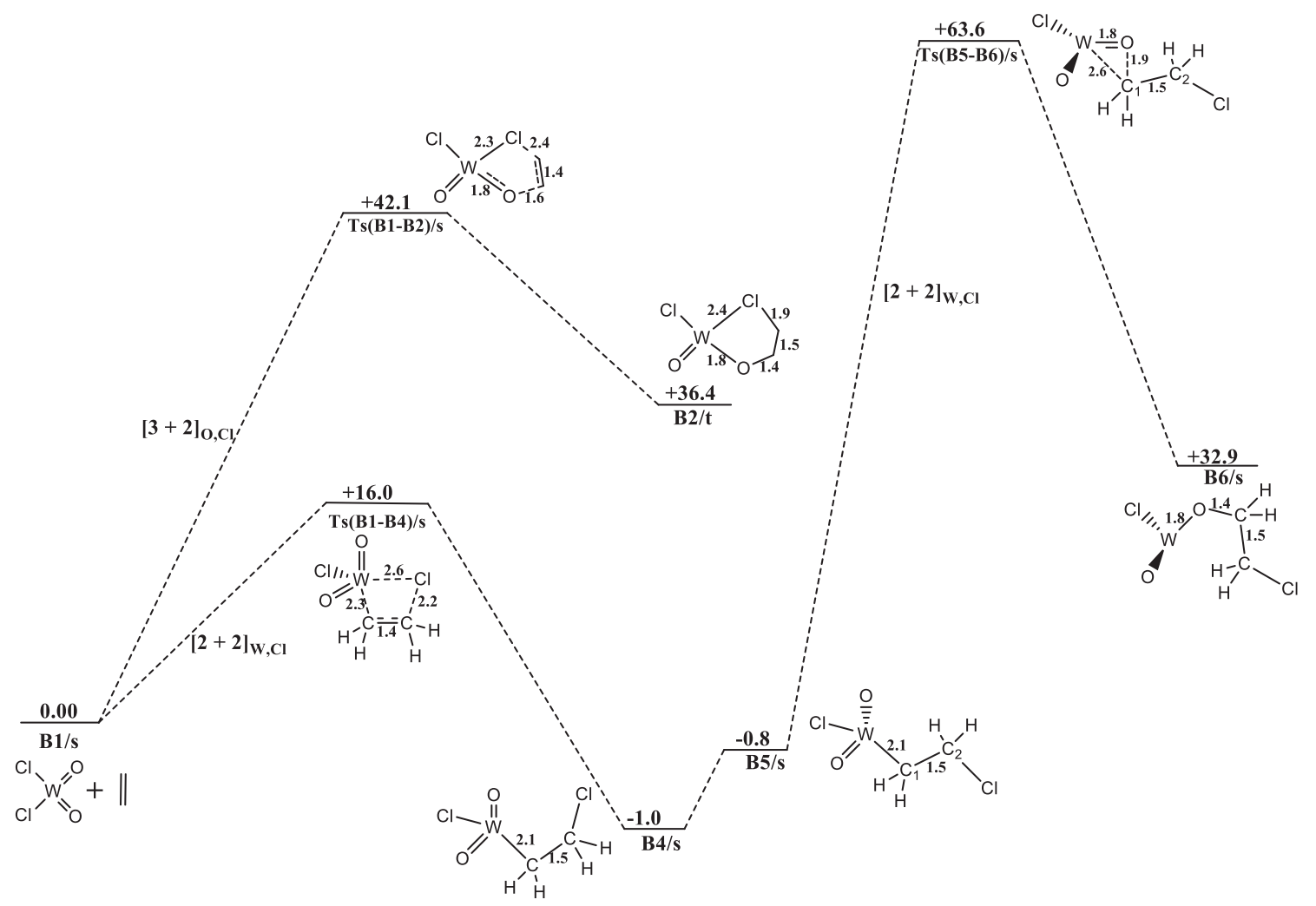

Figure 4. Reaction profile of mechanism for the formation of the 1,2-chlorohydrin precursor from the addition of $\mathrm{WO}_{2} \mathrm{Cl}_{2}$ to ethylene through the one step [3+2] pathway at the MO6 level. There is spin crossover intersystem crossing from the singlet reactant $\mathbf{B} 1 / \mathbf{s}$ to the triplet $\mathbf{B} 2 / \mathbf{t}$ ( $\mathrm{s}=$ singlet state, $\mathrm{t}=$ triplet). Energy in $\mathrm{kcal} / \mathrm{mol}$.

of theory. Furthermore, triplet $\mathbf{A 6}$ was not obtained at either B3LYP or MO6. Thus oxidation with $\mathrm{MoO}_{2} \mathrm{Cl}_{2}$ may lead to acetaldehyde and vinyl alcohol.

3.3b Tungsten complex: The singlet and triplet transition state TS [A5-X] for epoxide ring-opening are respectively found to be 64.8 and $65.7 \mathrm{kcal} / \mathrm{mol}$ above the reactants at the B3LYP level but at the MO6 level, the singlet was not located but the triplet was found to be $58.9 \mathrm{kcalmol}^{-1}$. Tia and Adei had earlier observed ${ }^{7}$ that the transition state $\mathbf{T S}$ [A5-X] could lead to the formation of $\mathbf{A} 7$ and that a 1,2-hydride shift from the secondary carbon to the terminal carbon of $\mathbf{A} 7$ could result in species A8, which could undergo W-O single bond cleavage to produce vinyl alcohol. Triplet and singlet A7 are $118.7 \mathrm{kcal} / \mathrm{mol}$ and $114.7 \mathrm{kcal} / \mathrm{mol}$ endothermic at B3LYP and $110.1 \mathrm{kcal} / \mathrm{mol}$ and $36.1 \mathrm{kcal} / \mathrm{mol}$ at MO6 levels, respectively. Species $\mathbf{A 8}$ was computed to be $48.5 \mathrm{kcal} / \mathrm{mol}$ and $39.9 \mathrm{kcal} / \mathrm{mol}$ endothermic at the B3LYP level for singlet and triplet state respectively, and $43.4 \mathrm{kcal} / \mathrm{mol}$ and $63.0 \mathrm{kcal} / \mathrm{mol}$ endothermic for the singlet and triplet states respectively at the MO6 level of theory.

The acetaldehyde precursor $\mathbf{A 6}$ has been obtained in optimizing A8 on the PES. Species A6 has energies of
20.1 and $22.6 \mathrm{kcal} / \mathrm{mol}$ for the singlet and triplet species respectively at B3LYP level and $17.6 \mathrm{kcal} / \mathrm{mol}$ and $17.6 \mathrm{kcal} / \mathrm{mol}$ on the singlet and triplet surfaces at the MO6 level. Limberg et al., ${ }^{37,38}$ found $\mathbf{A 6}$ an intermediate in the thermal reaction of ethylene with $\mathrm{CrO}_{2} \mathrm{Cl}_{2}$ and postulated it as a precursor to the formation of acetaldehyde, upon cleavage of the $\mathrm{Cr}-\mathrm{O}$ single bond. Thus the formation of acetaldehyde and vinyl alcohol from the oxidation with $\mathrm{WO}_{2} \mathrm{Cl}_{2}$ does not appear energetically feasible.

3.4 Comparison of the reactions of chromyl chloride, molybdyl chloride and tungstyl chloride with ethylene

Table 1 shows a comparison of the activation barriers of the various elementary reaction steps in the oxidation of ethylene with chromyl chloride, molybdyl chloride and tungstyl chloride. It is seen that the oxyhalides $\mathrm{MO}_{2} \mathrm{Cl}_{2}$ become weaker oxidants in the order $\mathrm{CrO}_{2} \mathrm{Cl}_{2}>>\mathrm{MoO}_{2} \mathrm{Cl}_{2}>\mathrm{WO}_{2} \mathrm{Cl}_{2}$. Corresponding to this, reactions involving reduction of the metal show a sharp increase in barrier going from $\mathrm{Cr}$ to $\mathrm{W}$ : this applies to the $[3+2]$ and $[2+1]$ reactions in table 1 . On the other and, reactions without a change in metal oxidation state $([2+2])$ show much smaller variations, 
Table 1. Activation barriers of the various elementary reaction steps in the oxidation of ethylene with chromyl chloride, molybdyl chloride and tungstyl chloride ${ }^{\mathrm{a}, \mathrm{b}}$.

\begin{tabular}{lcccccccc}
\hline & \multicolumn{7}{c}{ Activation barriers of reaction steps $(\mathrm{kcal} / \mathrm{mol})$} \\
\cline { 2 - 8 } Complex & {$[3+2]_{\mathrm{O}, \mathrm{O}}$} & {$[3+2]_{\mathrm{O}, \mathrm{Cl}}$} & {$[2+2]_{\mathrm{M}, \mathrm{O}}$} & {$[2+2]_{\mathrm{M}, \mathrm{Cl}}$} & {$[2+1]$} & $\mathrm{A} 3 \rightarrow \mathrm{A} 5$ & $\mathrm{~A} 2 \rightarrow \mathrm{A} 5$ & $\mathrm{~A} 4 \rightarrow \mathrm{A} 5$ \\
\hline $\mathrm{Cl}_{2} \mathrm{CrO}_{2}$ & 8.8 & 9.0 & 26.3 & 25.6 & - & 46.9 & 13.4 & 41.3 \\
$\mathrm{Cl}_{2} \mathrm{MoO}_{2}$ & 30.2 & 25.6 & 18.9 & 15.8 & 36.0 & 42.6 & 41.3 & 31.6 \\
$\mathrm{Cl}_{2} \mathrm{WO}_{2}$ & 49.5 & 42.1 & 16.9 & 16.0 & 59.3 & 44.5 & 65.9 & 24.7 \\
\hline
\end{tabular}

${ }^{a}$ Data for the Cr complex from ref. ${ }^{7}$ benergetics of the Cr complex at B3LYP level and for the Mo and W at MO6 level.

which are possibly mainly determined by sterics (reactions around $\mathrm{Cr}$ would suffer from steric congestion). It is seen that the barriers of the concerted $[3+2]_{\mathrm{O}, \mathrm{O}}$ and $[3+2]_{\mathrm{O}, \mathrm{Cl}}$ addition increase down the group 6 elements from $\mathrm{Cr}$ through Mo to $\mathrm{W}$ while the barriers for the $[2+2]_{\mathrm{M}, \mathrm{O}}$ addition decrease down the group, making the formation of the dioxylate more favourable in $\mathrm{Cr}$ and the formation of the metallaoxetane more favourable in W. For each of the complexes the barriers of the $[3+2]_{\mathrm{O}, \mathrm{O}}$ and $[3+2]_{\mathrm{O}, \mathrm{Cl}}$ are close but the $[3+2]_{\mathrm{O}, \mathrm{Cl}}$ route becomes more favoured as the group is descended. It is also seen that the conversion of the dioxylate intermediate to the epoxide precursor is not a very feasible step in any of the complexes. Also, while the barriers of the $[2+2]_{\mathrm{M}, \mathrm{O}}$ addition decrease down the group, the barriers for the conversion of the resulting metallaoxetane to the epoxide precursor increase sharply down the group, offsetting the feasibility of the formation of the epoxide precursor through initial $[2+2]_{\mathrm{M}, \mathrm{O}}$ addition. This makes the $\mathrm{Cr}$ complex the only complex where the epoxide precursor may arise from the initial $[2+2]_{\mathrm{M}, \mathrm{O}}$ addition even though that initial step has the highest barrier in the Cr complex.

\section{Conclusion}

The formation of an epoxide from the oxidation of ethylene with $\mathrm{MoO}_{2} \mathrm{Cl}_{2}$ and $\mathrm{WO}_{2} \mathrm{Cl}_{2}$ is not a very feasible process by any of the postulated pathways. If the epoxide precursor forms at all, it will arise via initial $[3+2]_{\mathrm{O}, \mathrm{Cl}}$ addition of ethylene across the $\mathrm{O}=\mathrm{M}-\mathrm{Cl}$ bonds of $\mathrm{MoO}_{2} \mathrm{Cl}_{2}$ and $\mathrm{WO}_{2} \mathrm{Cl}_{2}$ to form an intermediate, followed by re-arrangement to form the precursor $\left(\mathrm{Cl}_{2}(\mathrm{O}) \mathrm{M}-\mathrm{OC}_{2} \mathrm{H}_{4}\right)$, from which the epoxide can be generated by hydrolysis. The chlorohydrin precursor will originate from $[3+2]_{\mathrm{O}, \mathrm{Cl}}$ addition of ethylene across the $\mathrm{O}=\mathrm{M}-\mathrm{Cl}$ bonds of $\mathrm{MO}_{2} \mathrm{Cl}_{2}$. The results also indicate that a dichloride is not a likely product in the oxidation of ethylene by molybdyl chloride as none of the postulated intermediates, transition states and precursors for its formation have been located. However, in the case $\mathrm{WO}_{2} \mathrm{Cl}_{2}$ though no transition states could be located, a very stable dichloride precursor is formed, indicating that the formation of a dichloride may not be precluded. The formation of acetaldehyde and vinyl alcohol from the oxidation of ethylene does not appear energetically feasible with $\mathrm{MoO}_{2} \mathrm{Cl}_{2}$, but appears thermodynamically plausible with $\mathrm{WO}_{2} \mathrm{Cl}_{2}$. Thus, the oxidation of ethylene with $\mathrm{MoO}_{2} \mathrm{Cl}_{2}$ will most likely lead to the formation of chlorohydrins predominantly via $[3+2]_{\mathrm{O}, \mathrm{Cl}}$ addition; oxidation with $\mathrm{WO}_{2} \mathrm{Cl}_{2}$ may also form chlorohydrins, but only extremely slowly. Comparing these results with those of $\mathrm{CrO}_{2} \mathrm{Cl}_{2}$ reported earlier by us, it is seen that the oxyhalides $\mathrm{MO}_{2} \mathrm{Cl}_{2}$ become weaker oxidants in the order $\mathrm{CrO}_{2} \mathrm{Cl}_{2}>>\mathrm{MoO}_{2} \mathrm{Cl} 2>$ $\mathrm{WO}_{2} \mathrm{Cl}_{2}$. Corresponding to this, reactions involving reduction of the metal show a sharp increase in barrier going from $\mathrm{Cr}$ to $\mathrm{W}$ : this applies to the $[3+2]$ and $[2+1]$ reactions. On the other and, reactions without a change in metal oxidation state $([2+2])$ show much smaller variations, which are possibly mainly determined by sterics (reactions around $\mathrm{Cr}$ would suffer from steric congestion). There are a number of singlet-triplet spin crossover in the course of the oxidation reactions studied, showing the importance of multiple spin states in this class of organometallic reactions. The MO6 and B3LYP functionals have been found to give similar activation barriers for most of the steps but the MO6 predicts more stable intermediates and products than the B3LYP.

\section{Supplementary Information}

Energy profiles and optimized geometrical parameters of all the stationary points involved in the reactions reported. Figures S1-S16 are available as Supplementary Information at www.ias.ac.in/chemsci.

\section{Acknowledgements}

The authors are very grateful to the National Council for Tertiary Education, Republic of Ghana, for a research grant under the Teaching and Learning Innovation Fund (TALIF/KNUST/3/008/2005). RT and EA conceived the idea and designed the study. RT, EA, JB 
and JE ran calculations and analyzed data. RT and EA wrote the manuscript.

\section{References}

1. W Mijs and C R Jonge 1986 (Eds.) In Organic synthesis by oxidation with metal compound (New York: Plenum)

2. Crans D C, Chen H and Felty R A 1992 J. Am. Chem. Soc. 1144543

3. Sharpless K B, Teranishi A Y and Bäckvall J E 1977 J. Am. Chem. Soc. 993120

4. Schröder M 1980 Chem. Rev. 80187

5. Pidun U, Boeheme C and Frenking G 1996 Angew. Chem. Int. Ed. Engl. 352817

6. Ziegler T, Torrent M, Deng L, Duran M and Sola M 1997 Organometallics 1613

7. Tia R and Adei E 2009 Inorg. Chem. 4811434

8. Tia R and Adei E 2011 Comput. Theor. Chem. 977140

9. Aniagyei A, Tia R and Adei E 2013 Dalton Trans. 42 10885

10. Aniagyei A, Tia R and Adei E 2013 Dalton Trans. 42 14411

11. Aniagyei A, Tia R and Adei E 2013 Comput. Theor. Chem. 100970

12. Criegee R 1936 Justus Liebigs Ann. Chem. 52275

13. Criegee R, Marchaand B and Wannowius H 1942 Justus Liebigs Ann. Chem. $\mathbf{5 5 0} 99$

14. Corey E J, Jardine P D, Virgils S, Yuen P-W and Connell R D 1989 J. Am. Chem. Soc. 1119243

15. Corey E J, Noe M C and Sarshar S 1993 J. Am. Chem. Soc. 1153828

16. K B Wiberg 1965 (Ed.) Oxidation in Organic Chemistry. Part A (New York: Academic Press) pp. 1-68

17. Wallis J M and Kochi J K 1988 J. Am. Chem. Soc. 110 8207
18. Gable K P and Phan T N 1994 J. Am. Chem. Soc. 116 833

19. Rappé A K and Goddard W A III 1982 J. Am. Chem. Soc. 1043287

20. Dapprich S, Ujaque G, Maseras F, Lledós A, Musaev D $\mathrm{G}$ and Morokuma K 1996 J. Am. Chem. Soc. 11811660

21. Wu Y-D, Wang Y and Houk K N 1992 J. Org. Chem. 57 1362

22. Torrent M, Deng L and Ziegler T 1998 Inorg. Chem. 37 1307

23. Torrent M, Deng L, Duran M, Solá M and Ziegler T 1999 Can. J. Chem. 771476

24. Strassner T and Drees M 2004 J. Mol. Struct: THEOCHEM 671(1-3) 197

25. Spartan, Wavefunction, Inc., 18401 Von Karman Ave., \#370, Irvine, CA, 92715, USA

26. Becke A D 1988 Phys. Rev. A 383098

27. Becke A D 1996 J. Chem. Phys. 1041040

28. Lee C, Yang W and Parr R G 1988 Phys. Rev. B 37785

29. Vosko S H, Wilk L and Nusair M 1980 Can. J. Phys. 58 1200

30. Zhao Y and Truhlar D G 2008 Theor. Chem. Account 120215

31. Peverati R and Truhlar D G Phil. Trans. R. Soc. A 372 20120476

32. Dunning T H Jr, Hay P J 1976 In Modern Theoretical Chemistry 3 H F Schaefer III (Ed.) (New York: Plenum)

33. Hay P J and Wadt W R 1985 J. Chem. Phys. 82270

34. Wadt W R and Hay P J 1985 J. Chem. Phys. 82284

35. Hay P J and Wadt W R 1985 J. Chem. Phys. 82299

36. Roy L E, Hay P J and Martin R L 2008 J. Chem. Theory Comput. 41029

37. Limberg C and Köppe R 1999 Inorg. Chem. 382106

38. Limberg C, Köppe R and Schnöckel H 1998 Angew. Chem. Int. Ed. 37496 